\title{
PERSPECTIVAS DA PROTEÇÃO AO MEIO AMBIENTE ANTE O ESTATUTO DA CIDADE
}

Perspectives of environmental protection under the City Statute

\section{Suelem da Costa Silva}

e-mail suelemcosta112@yahoo.com.br

Advogada, Universidade de Santa Cruz do Sul- UNISC., Santa Cruz do Sul, RS, Brasil

Mestranda em Direito

\section{Clovis Gorczevsk}

e-mail clovisg@unisc.br.

Advogado, Doutor em Direito (Universidad de Burgos 2002), pós-doutor pela Universidad de Sevilla (CAPES 2007) e pela Universidad de La Laguna (CAPES/FUNDACIÓN CAROLINA 2011). Professor da Universidade de Santa Cruz do Sul.

\section{RESUMO}

O presente artigo emprega o método de revisão de literatura com a finalidade de analisar o Estatuto da Cidade após 20 anos de sua vigência, considerando o objetivo da proteção ambiental no espaço urbano. Parte-se da premissa de que o Estatuto da Cidade representa um marco normativo e principiológico para a proteção ambiental coadunando com o esforço institucional internacional em conciliar economia e sustentabilidade. Fixa-se o objetivo de apontar de que forma o Estado está responsabilizado para com políticas públicas de proteção ambiental, como transcorre a mobilização política e social e a formulação de práticas protetivas com centralidade no direito ambiental. Busca-se especificar como a Política Nacional do Meio Ambiente coaduna com o Estatuto da Cidade permitindo que o Estado brasileiro responda as demandas de sustentabilidade à nível local, regional e nacional. Incluso, verifica-se de que forma o Estatuto responde a Agenda 2030 e aos Objetivos de Desenvolvimento Sustentável, coadunando princípios do direito urbanístico e do direito ambiental. Entende-se que no âmbito das perspectivas de proteção ambiental a partir do Estatuto da Cidade tem-se a sedimentação principiológica da proteção dos recursos ambientais e a consolidação de um processo de urbanização que respeita as funções sociais da cidade, demandando-se, apenas uma maior mobilização social e um esforço político extensivo em prol do ambiente urbano sustentável.

Palavras-chave: Estatuto da Cidade. Sustentabilidade. Cidades sustentáveis. Meio ambiente. Direito urbanístico.

\section{ABSTRACT}

This article uses the literature review method in order to analyze the City Statute after 20 years of its validity, considering the objective of environmental protection in the urban space. It starts from the premise that the City Statute represents a normative and principled framework for environmental protection, in line with the international institutional effort to reconcile economy and sustainability. The objective is to point out how the State is responsible for public policies for environmental protection, 
how political and social mobilization and the formulation of protective practices with centrality in environmental law take place. It seeks to specify how the National Environmental Policy complies with the City Statute, allowing the Brazilian State to respond to sustainability demands at local, regional and national levels. In addition, it is verified how the Statute responds to the 2030 Agenda and the Sustainable Development Goals, joining principles of urban law and environmental law. It is understood that within the scope of environmental protection perspectives from the City Statute there is the principled sedimentation of the protection of environmental resources and the consolidation of an urbanization process that respects the social functions of the city, requiring only one greater social mobilization and an extensive political effort in favor of a sustainable urban environment.

Keywords: City Statute. Sustainability. Sustainable cities. Environment. Urban planning law.

\section{INTRODUÇÃO}

Essa pesquisa tem o objetivo de analisar as disposições do Estatuto da Cidade considerando a proteção do meio ambiente urbano. Entre os objetivos desse artigo que utiliza o método de revisão da literatura especializada com a análise de artigos científicos oriundos do Scielo, Dialnet e Google Acadêmico, além de livros da matéria, encontra-se o apontamento do conceito e das dimensões do espaço urbano, do desenvolvimento sustentável, dos princípios do direito urbanístico, dos princípios do direito ambiental e do panorama da defesa do espaço urbano sustentável mediante o Estatuto da Cidade.

Se entende que o Estatuto da Cidade representa um marco normativo e principiológico em direção a proteção ambiental. Nesse sentido, essa norma que cumpre 20 anos de vigência coaduna com o esforço institucional internacional em conciliar economia e sustentabilidade. Verifica-se, a partir da apresentação do histórico de proteção ambiental e da aferição do meio ambiente como um bem jurídico imprescindível à humanidade e que, ainda, contém um valor em si, o Estado está responsabilizado para com políticas públicas de proteção ambiental.

A responsabilidade do Estado para o com o meio ambiente implica na consolidação de um instrumento normativo que efetive essa proteção no espaço urbano. Desse modo, entende-se que o Estatuto da Cidade advém como resposta a essa obrigação jurídica do Estado para com o meio ambiente e proporciona um arcabouço principiológico, de estratégias para políticas públicas e institucionais que implementam a sustentabilidade a nível local.

Demonstra-se que o Estatuto da Cidade coaduna a Agenda 2030 e com os Objetivos de Desenvolvimento Sustentável permitindo a intersecção entre os princípios do direito urbanístico e do direito ambiental. Considerando as perspectivas de proteção ambiental a partir do Estatuto da Cidade sedimenta-se a base principiológica da proteção dos recursos ambientais ainda que se demande uma maior mobilização social e um esforço político extensivo em favor do ambiente urbano sustentável.

\section{ESTRUTURA}

\subsection{Espaço urbano e desenvolvimento sustentável}

O espaço urbano ocupa um importante papel na organização social, permitindo a interação dos indivíduos dentro de um complexo sistema de serviços e atividades. As cidades permitem a coordenação 
das ações dos indivíduos e das instituições. Ocorre que as ações humanas dependem das informações do ambiente, de modo que a cidade constitui um ambiente de informação (NETTO; MEIRELLES; RIBEIRO, 2018). O espaço urbano pode ser conceituado, no bojo do capitalismo, como um espaço fragmentado, articulado, reflexo, condicionante social, permeado de símbolos e campo de lutas. Se trata de um produto social que advém de ações que se acumulam no decurso do tempo e que são impulsionadas por agentes que produzem e que consomem esse espaço (CORREA 2004).

O desenvolvimento precisa estar direcionado para a melhoria da qualidade de vida e não apenas para o crescimento econômico sob pena de não figurar, de fato, como desenvolvimento, mas como uma fragilidade no sistema. Um maior desenvolvimento depende da manutenção dos recursos naturais a partir da conciliação entre aportes econômicos e o empenho na conservação ambiental. Uma estratégia para o desenvolvimento econômico e social deve pautar o direcionamento final da sociedade e a sua trajetória econômica considerando a máxima da qualidade de vida para todos (SICSU, 2009). Reforça-se que o Poder Público, a sociedade e a inciativa privada estão dispostas enquanto atores de responsabilidade na harmonização das finalidades econômicas, ambientais e sociais.

Abaixo figura-se os pilares do desenvolvimento sustentável que devem ser integrados no planejamento urbano permitindo-se a eficiência de recursos a partir de uma racionalidade econômica que respeite a proteção ambiental.

Figura 1 - Pilares do Desenvolvimento Sustentável.

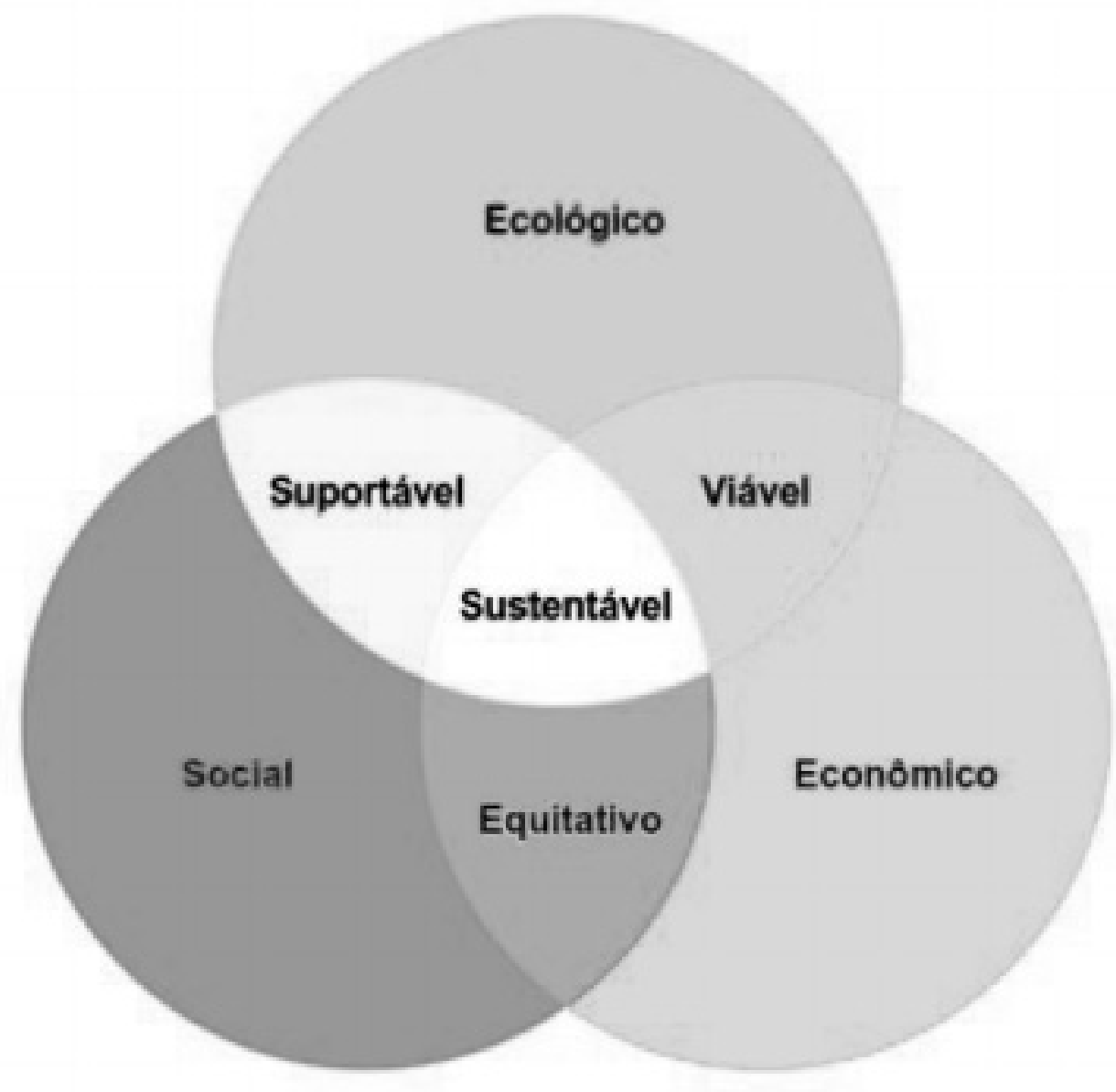

Fonte: Silva (2018) 
A responsabilidade do Estado implica uma dimensão operacional que proporcione aos órgãos da administração direta e indireta, em seus três níveis de governo, uma capacidade extensiva para implementar de forma eficiente e eficaz as políticas públicas de proteção ambiental. No Brasil tem-se um crescente número de instituições que concebem e formulam diagnósticos, análises e avaliações e que visam aproximar as suas práticas protetivas do escopo de políticas internacionais. A partir de uma visão crítica acerca das políticas territoriais no país, entende-se que falta mobilização social e política para ultrapassar os obstáculos institucionais, a intensidade administrativa dos instrumentos baseados em mercado e as reformas baseadas em mercado para pautar sobretudo a centralidade do meio ambiente (HADDAD, 2015).

A cidade se estrutura desde uma rede de processos em um tempo humano e natural, o que implica considerar que na cidade se encontram sobrepostos os vieses mecânico e natural do mundo. A sustentabilidade urbana envolve considerar cada população, a sua história e especificidades, a identidade, os valores e a ética dispostas nos territórios. Integra-se a representação tecno-material das cidades, a questão da cidade como espaço de qualidade de vida e a noção de que sistemas de sustentabilidade implicam a realidade de cada nação para mensurar políticas públicas urbanas que integrem o respeito ao meio ambiente (SCOPEL, 2018).

A proteção ambiental de estabelece principalmente sob quatro pilares, a Constituição Federal, a Política Nacional do Meio Ambiente, A Lei de Ação Civil Pública e a Lei de Crimes Ambientais. De acordo com a Constituição Federal existem alguns espaços territoriais especialmente protegidos de acordo com o art. 225, 1, inciso III. Pela mensuração desses espaços busca-se efetivar o direito ao meio ambiente ecologicamente equilibrado. Um paralelo desse instituto são os spaces natureis sensibles no direito francês, fiscalizados pelo Ministério da Ecologia e do Desenvolvimento Sustentável da França. Nisso se entende que o meio ambiente ecologicamente equilibrado integra o meio urbano, o seu patrimônio histórico e cultural, parques e rios, o meio natural que participa da vida dos indivíduos nas cidades (PEREIRA; SCARDUA, 2008).

A Política Nacional do Meio Ambiente se pauta a partir do esforço em integrar a democracia e a proteção ambiental a partir de um marco normativo consistente. Nesse viés, aponta-se:

O grande marco da adolescência do direito urbanístico brasileiro será a promulgação da Constituição de 1988, que afirmará sua existência e fixará seus objetivos e instrumentos.9 O direito urbanístico veio a ser tratado como disciplina jurídica pelo art. 24, que conferiu expressamente à União competência legislativa para editar suas normas gerais (inc. I $c / c \$ 1^{\circ}$ ), deixando aos Estados a competência suplementar $\left(\$ 2^{\circ}\right)$, existente também em favor dos Municípios (art. 30, II). Só que o mero status constitucional, embora importante, não contribui muito para resolver o dilema existencial de todo ramo jurídico, o de seu critério diferenciador. Decidir se um tema, instrumento ou norma deve ser enquadrado no direito urbanístico, no direito civil ou no direito local pode ser um desafio insuperável, tendo como reflexo a indefinição quanto ao titular da competência legislativa (se o direito em causa for urbanístico, a União só fará normas gerais; se for o civil, terá toda a competência normativa; se a matéria for estritamente local, competente será exclusivamente o Município). Desse modo, continua sendo útil debater a respeito da identidade - e, portanto, da autonomia - do direito urbanístico, pois disso depende a solução, quando menos, de muitas dúvidas relativas à competência. Nesse contexto, têm grande relevância as normas, também constitucionais, tratando dos objetivos e instrumentos da política urbana. (SUNDFELD, 2006, p. 04) 
No bojo normativo de confluência entre espaço urbano e desenvolvimento sustentável destaca-se a Agenda 2030 e os Objetivos de Desenvolvimento Sustentável (ODS) de 2015 em que se figura um pacto supranacional para o enfrentamento de desafios globais. o Brasil juntamente com outros 193 Estados-membro da Organização das Nações Unidas (ONU) assinam esse acordo para promover a prosperidade econômica, o desenvolvimento social e a proteção ambiental. No cenário nacional, observa-se que ainda que não se considere os efeitos do COVID-19 nas cidades brasileiras, deve-se acelerar os projetos públicos para que se efetive os ODS. Essas alterações devem considerar principalmente o campo da saúde e bem-estar, educação de qualidade, igualdade de gênero, redução de desigualdades, paz, justiça e instituições eficazes, as desigualdades territoriais do país e o agravamento do desmatamento (IDSC-BR, 2021).

Entende-se que há um histórico normativo que busca pautar a sustentabilidade no espaço urbano. Esse histórico, como aponta Barros et al (2012) remete a Conferência das Nações Unidas sobre o Meio Ambiente Humano (Declaração de Estocolmo) de 5 a 16 de junho de 1972 na Suécia. Esse marco histórico-normativo implicou em uma alteração na postura sobre o meio ambiente inaugurando um período de maiores preocupações sobre o direito ambiental. A Conferência pautou a demanda por orientação da comunidade em direção a proteção do meio ambiente, principalmente quanto à poluição advinda das atividades industriais.

Considerava-se o contraponto entre o avanço urbano e estratégias de desenvolvimento social e econômico condizentes com um meio ambiente integro. Criou-se a base principiológica de 26 normas para garantir o uso equilibrado de recursos ante o crescente consumo, a produção e a qualidade de vida. A Conferência de Estocolmo impulsionou outras conferências nesse campo e salientou o esforço institucional em prol da proteção do meio ambiente em todos os territórios, incluso o território urbano, como salienta Barros et al (2012).

Posto esse histórico do esforço institucional e normativo em zelar pelo desenvolvimento urbano a partir dos marcos da proteção ambiental, a próxima seção aprofunda quais são os substratos principiológicos do direito urbanístico e do direito ambiental.

\subsection{Substratos principiológicos do direito urbanístico e do direito ambiental}

A análise dos princípios do direito é importante para compreender melhor os institutos e instrumentos jurídicos. Os princípios possuem o condão de estruturar o ordenamento, vinculando valores jurídicos suprapositivos. Os princípios se caracterizam por sua eficácia, aplicabilidade, são instrumentos de controle das práticas dos Poderes do Estado (OLIVEIRA; BRANDÃO, 2019). No escopo do direito urbanístico, os princípios que integram as dinâmicas nesse campo podem ser elencados pelo princípio da função social da propriedade imóvel urbana, a função social da cidade, a solidariedade urbana, a democratização da política urbana, a preeminência do Plano Direto e do planejamento, o compartilhamento das responsabilidades públicas em política urbana, a essencialidade da moradia adequada e a sustentabilidade urbana (BRUNO FILHO, 2015).

A função social da propriedade imóvel urbana agrupa as searas do direito de propriedade, ao meio ambiente ecologicamente equilibrado e a sadia qualidade de vida. A função social da propriedade implica em um direito fundamental, um princípio jurídico e efetiva os seus efeitos em conjunto com a função socioambiental da propriedade urbana (HUMBERT, 2011). Aponta-se que desde 1934, 
mediante os textos constitucionais, observa-se a previsão normativa da função social da propriedade urbana, integrando a participação ativa dos movimentos da sociedade civil e as pautas da moradia digna, da infra-estrutura, do acesso de serviços públicos, da igualdade, do respeito à diferença e ao meio ambiente saudável (RODRIGUES, 20704).

Entende-se que:

[...] princípios como o da natureza pública da proteção ambiental, da participação comunitária, da responsabilidade, da prevenção, da inclusão da variável ambiental nas decisões sobre política pública de desenvolvimento e do desenvolvimento sustentável orientam também as políticas de proteção ao patrimônio cultural. O equilíbrio ambiental a ser garantido está relacionado com a adequação entre o aspecto dinâmico da cultura e eleição de exemplares significativos a proteger. E diversos são os critérios, não apenas o histórico, a serem levados em consideração para a decisão por preservar. (MORETTI, 2006, p. 110)

A função social da cidade está posta como uma garantia de direitos fundamentais disposta pelos arts. 182 e 183 da CF/88. Esse parâmetro é posto diante da percepção de avanço da globalização, de desenvolvimento de novas tecnologias ante o panorama do século XX. Esse quadro reforça a subjugação da natureza ante um racionalismo humano e a fragilidade dos direitos sociais perante o individualismo exacerbado. Desse cenário percebe-se uma maior degradação da natureza a segregação social ante a população mais pobre da sociedade. A natureza, nesse cenário, é vista como um instrumento para a supressão das demandas humanas e não um ente em si, dotado de dignidade. Demanda-se, assim, que se observe a função social da sociedade para sedimentar uma infraestrutura urbana que atenda aos direitos da população, aos direitos sociais e a proteção ambiental (COSTA; VENÂNCIO, 2016).

A solidariedade urbana está disposta em consonância com a solidariedade social em que se tem o compromisso de preservação do meio ambiente em vista da presente e das futuras gerações. Assim, mediante o marco da solidariedade é possível realizar a defesa da configuração urbana solidária e a sua compatibilidade com o Estatuto da Cidade. Concebe-se que existe algumas discrepâncias principiológicas entre o modo de vida capitalista, individualista e o modo de vida coletivista e solidário, assim é preciso buscar as premissas de um capitalismo sustentável em que ocorra o equilíbrio entre economia, justiça social e meio ambiente, como aponta Santiago e Peixoto (2019).

A democratização da política urbana está pautada desde a consideração de que o Estatuto da Cidade parte do movimento de democratização do país. Entende-se que o direito a cidade integra a ampliação de direitos no país, integrando lutas urbanas, pela saúde, pelo transporte, pelo saneamento, pela educação e pelo meio ambiente saudável. Figura a subordinação da propriedade privada às finalidades da política urbana aprofundando o exercício da governança democrática no bojo do Estatuto da Cidade (AVRITZER, 2010). Ocorre uma sobreposição da agenda da reforma urbana sobre o desenvolvimento urbano, buscando desvincular a ordem social de uma lógica de acumulação predatória. Historicamente, a democratização promovida pelo Estatuto da Cidade veio acompanhada da criação de alguns institutos tais como Sistema Financeiro de Habitação (SFH), Banco Nacional de Habitação (BNH), Serviço Federal de Habitação e Urbanismo (Serfhau) (GOULART; TERCI; OTERO, 2015),

A preeminência do Plano Direto e do planejamento está disposto a partir do art. 4 do Estatuto da Cidade ao apresentar como instrumento de política urbana os planos nacionais, regionais e estaduais de ordenação do território e desenvolvimento econômico e social. O plano permite a concretização 
do uso e ocupação do solo, do zoneamento ambiental, do orçamento público e estabelece uma gestão participativa (MUKAI, 2005).

O compartilhamento das responsabilidades públicas em política urbana demanda a incorporação de diferentes sujeitos por meio de processos democráticos participativos, conselhos, conferências. É preciso criar um diálogo com responsabilidade para desenhar o destino dos recursos e da política urbana sustentável. Todavia, ainda se considera que "Apesar da intensidade das propostas e do envolvimento de sujeitos coletivos na construção de um sistema nacional de desenvolvimento urbano, os avanços são lentos com disputas de projetos muitas vezes conflitantes." (TONELLA, 2013, p. 49).

A essencialidade da moradia adequada é disposto como um direito humano, sedimentado internacionalmente pelo Pacto Internacional sobre Direitos Civis e Políticos, pelo Pacto Internacional sobre Direitos Econômicos, Sociais e Culturais e pelo Comentário Geral no 4 do Comitê de Direitos Econômicos, Sociais e Culturais. No Brasil, como exposto, está orientado por força da Constituição Federal de 1988, o Estatuto da Cidade, a Lei no 11.124 de 2005, Lei no 11.481 de 2007 (SDH, 2013).

Nesse sentido, implica a segurança de posse, a disponibilidade de serviços, materiais, instalações e infraestrutura, a habitabilidade que considera o espaço adequado, a proteção contra frio, umidade, calor, chuva, vento e outras ameaças à saúde. Integra-se também a acessibilidade, a localização - de modo que a moradia deve estar próxima as oportunidades de emprego, serviços de saúde, escolas, instalações sociais e não estar próximo a áreas poluídas ou perigosas, além de uma adequação cultural (SDH, 2013).

A sustentabilidade urbana é um dos objetivos do desenvolvimento sustentável, considerada como um processo de interesse global, ainda que envolva objetivos locais e funciona como um elemento para contrapor graves desigualdades econômicas e sociais. Considera-se as áreas urbanas enquanto sistemas físicos, funcionais e energéticos interdependentes, um espaço que mobiliza diversos campos e disciplinas e com impacto global. A elevada urbanização está adjunta com mudanças climáticas e se contrapõe aos desafios de sustentabilidade, de modo que pautar a sustentabilidade urbana é importante. Desse modo, se entende que a Política Nacional de Meio Ambiente e o Estatuto da Cidade contribuem como instrumentos preservação e proteção ambiental no espaço urbano, como trata Sotto (2019).

No escopo do direito ambiental figuram os princípios do desenvolvimento sustentável, o princípio da dignidade, do meio ambiente de qualidade, da reparação integral, da prevenção e da precaução, princípio da obrigatoriedade da intervenção do Poder Público, o princípio da informações à disposição de todos, o princípio da participação social e comunitária, da função socioambiental da propriedade, da solidariedade intergeracional, da natureza pública da proteção ambiental, da cooperação e da proibição de retrocesso (ARRUDA, 2014).

O desenvolvimento sustentável como princípio do Direito Ambiental é reforçado dentro da jurisprudência nacional, a saber:

O princípio do desenvolvimento sustentável, além de impregnado de caráter eminentemente constitucional, encontra suporte legitimador em compromissos internacionais assumidos pelo Estado brasileiro e representa fator de obtenção do justo equilíbrio entre as exigências da economia e as da ecologia, subordinada, no entanto, a invocação desse postulado, quando ocorrente situação de conflito entre valores constitucionais relevantes, a uma condição inafastável, cuja observância não comprometa nem esvazie o conteúdo essencial de um dos mais significativos 
direitos fundamentais: o direito à preservação do meio ambiente, que traduz bem de uso comum da generalidade das pessoas, a ser resguardado em favor das presentes e futuras gerações (...). A atividade econômica não pode ser exercida em desarmonia com os princípios destinados a tornar efetiva a proteção ao meio ambiente. (ADI 3.540/DF apud SILVA, 2017, p. 04)

$\mathrm{Na}$ intersecção entre os princípios do direito urbanístico e os princípios do direito ambiental é possível destacar aqueles que apresentam uma íntima relação, entre os quais o Princípio da sustentabilidade econômica, social e ambiental que devem nortear as políticas públicas urbanas, considerando um capitalismo socioambiental que atenda aos objetivos da República Federativa do Brasil, quais sejam: a construção de uma sociedade livre, justa e solidária. Reforça-se que o princípio da sustentabilidade econômica, social e ambiental está posto como um eixo para a estruturação de uma cidade sustentável (OLIVEIRA; BRANDÃO, 2019).

Assentado os pressupostos normativos, históricos e sociais que possibilitam pensar a premissa da sustentabilidade no espaço urbano, e dispostos os princípios que figuram no direito urbanístico e no direito ambiental, a próxima seção aponta as perspectivas da proteção ambiental a partir do Estatuto da Cidade.

\subsection{Perspectivas da proteção ambiental a partir do Estatuto da Cidade.}

O Estatuto da Cidade constitui um marco na normatização da política urbana. A sua interface com a proteção ambiental se pauta sobretudo com o planejamento e controle do uso e ocupação do solo urbano. Nesse campo, ressalta-se a correspondência da norma com as demandas dos movimentos que demandam a reforma urbana considerando o viés constitucional observado no Estatuto da Cidade. Existe uma relação entre o ambiente natural e o ambiente construída que ressalta alguns desequilíbrios entre esses dois ambientes.

Pontua-se que "alguns municípios pioneiros instituíram suas políticas municipais de meio ambiente como um dos mecanismos do Poder Público local para definir diretrizes e estabelecer normas na forma de lei que regulamenta as questões ambientais locais” (IBGE, 2002, p. 20). Essa premissa denota o quanto é importante coadunar as demandas ambientais em âmbito local, dentro das cidades, como um objetivo institucional que pode ser executado por gestores, sociedade civil e o corpo político de forma local. Esse intento histórico pelos municípios em executar políticas públicas de proteção do meio ambiente no espaço urbano pode ser efetivado mediante o Estatuto da Cidade, considerando as premissas desse documento legislativo, tais como:

Art. 2ํ A política urbana tem por objetivo ordenar o pleno desenvolvimento das funções sociais da cidade e da propriedade urbana, mediante as seguintes diretrizes gerais: IV - planejamento do desenvolvimento das cidades, da distribuição espacial da população e das atividades econômicas do Município e do território sob sua área de influência, de modo a evitar e corrigir as distorções do crescimento urbano e seus efeitos negativos sobre o meio ambiente; (PLANALTO, 2001, online)

Esse desequilíbrio se dá principalmente pela urbanização territorial desenfreada, a especulação imobiliária dos grandes centros urbanos e a devastação dos entornos naturais. Demanda-se uma política nacional de desenvolvimento urbano que sedimente a proteção dos recursos ambientais, atenda as demandas de sustentabilidade, de modo que o Estatuto da Cidade cumpre uma função essencial, 
como trata Torres (2006). Pontua-se que "não obstante, em que pese a segmentação temporal de suas atividades, o Estado deve utilizar-se de todas as suas estruturas na busca do meio ambiente ecologicamente equilibrado" (SILVA; CUNHA, 2020, p. 19).

Um ponto importante da consideração da sustentabilidade no escopo do espaço urbano está nas iniciativas de agricultura nas cidades. Esse espaço se desenvolve ante a ideia de um continuum entre o meio rural e urbano em que não se considera uma divisão agudo entre as áreas, ainda que a delimitação político-administrativa adotada no país segue os exemplos do Reino Unido, da Tunísia e da África do Sul e colocam limites oficiais na diferenciação territorial (IBGE, 2017).

Entende-se, como aponta Alfonsin (2001) que o Estatuto da Cidade foi promulgado após uma década de lutas por reforma urbana no país. Ocorre que essa normativa considera a história de produção das cidades e se posiciona como instrumento normativo de intervenção da realidade com a finalidade de promover transformações. Reforçam-se, como exposto, as diretrizes gerais da lei com o escopo da gestão democrática, da sustentabilidade urbano-ambiental, da cooperação entre os múltiplos campos sociais e consolidação de um processo de urbanização que paute as funções sociais da cidade.

De forma prática, o Estatuto da Cidade permite, por meio de seus instrumentos de políticas públicas, contabilizar as intervenções ambientais em prol do meio socioambiental. Abaixo tem-se as disposições dessa contabilização no qual se consideram impactos, externalidades e dano, além das possibilidades de compensação ambiental, financeira e de reparação civil no trata com o meio ambiente. Entende-se que no esforço institucional de proteção do meio ambiente, o Estatuto da Cidade permite pensar essas variáveis dentro do espaço urbano e alcançar práticas sustentáveis.

Figura 2 - Esquema das Forças Contrárias na Análise de Intervenções Ambientais.
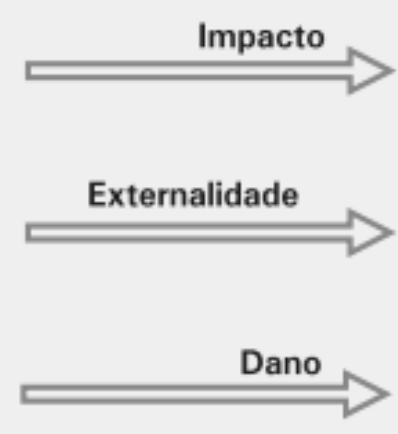

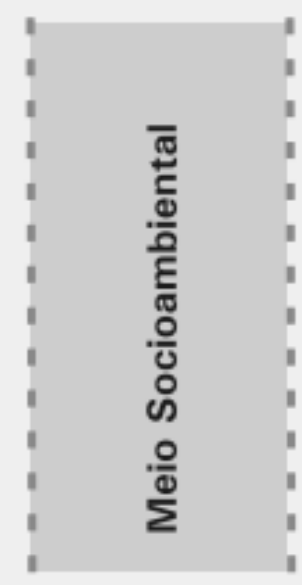

Compensação Ambiental

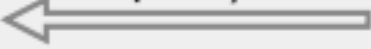

Compensação Financeira

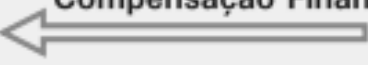

Reparação Civil

Fonte: Portela (2016) apud IBAMA (2020).

O Estatuto da Cidade estabelece alguns instrumentos para a proteção do meio ambiente natural tal como a gestão democrática no qual se estruturam conselhos de políticas urbana, a iniciativa popular de leis, a realização de debates, audiências e consultas públicas. No escopo do plano diretos tem-se a exigência em especificar áreas de interesse turístico e o impacto ambiental nesses setores; fixa-se o direito a superfície, o direito de preempção, a outorga onerosa do direito de construir e de alterar o uso, as operações urbanas consorciadas, a transferência do direito de construir e o estudo do impacto 
de vizinhança para consolidar um espaço urbano que se contraponha a um ambiente ferozmente competitivo e socialmente perverso, como trata Bassul (2002).

No bojo dos princípios do Estatuto da Cidade, aponta Rodrigues (2004) se encontram possibilidades e virtualidades que proporcionam a edificação de um Direito à Cidade ideal. Subsistem controvérsias e conflitos para o planejamento do uso do território urbano no qual se observa conflitos acerca do uso do espaço público em consonância com as disposições culturais, de gênero, de etnia, de trabalho e de segurança que podem ser resolvidas mediante a ação política-normativa da sociedade civil organizada.

Passados 20 anos da elaboração do Estatuto da Cidade subsiste a preocupação ambiental como um elemento importante da manutenção e gestão pública do espaço urbano. A proteção do espaço urbano ambiental pelo Estatuto da Cidade implica o planejamento do desenvolvimento das cidades considerando a distribuição espacial da população, as atividades econômicas do município, o crescimento urbano e os seus efeitos sobre o meio ambiente. O Estatuto da Cidade impõe a proteção, a preservação e a recuperação do meio ambiente natural considerando os parâmetros da segurança populacional. Entende-se que o Estatuto da Cidade cumpre com a tarefa de apresentar uma base principiológica consistente para a proteção ambiental no espaço urbano, ainda que se demanda mobilização social e ação política ante os parâmetros apontados pela norma jurídica.

\section{REFERÊNCIAS}

ALFONSIN, Betania. O Estatuto da cidade e a construção de cidades sustentáveis, justas e democráticas. Direito e Democracia 309, 2001. Disponível em: http://www.periodicos.ulbra.br/index.php/direito/ article/view/2405/1640. Acesso: 26 ago. 2021.

ARRUDA, Carmen Silvia Lima de. Princípios do direito ambiental. Revista CEJ, Brasília, Ano XVIII, n. 62, p. 96-107, jan./abr. 2014. Disponível em: https://journals.openedition.org/rccs/4491. Acesso: 26 ago. 2021.

AVRITZER, Leonardo. O Estatuto da Cidade e a democratização das políticas urbanas no Brasil. Revista Crítica de Ciências Sociais, 91, 2010, 205-221. Disponível em: https://journals.openedition.org/ rccs/4491. Acesso: 26 ago. 2021.

BARROS et al, Dalmo Arantes. Breve análise dos instrumentos da política de gestão ambiental brasileira. Política \& Sociedade - Florianópolis - Vol. 11 - o 22 - Novembro de 2012. Disponível em: https://periodicos.ufsc.br/index.php/politica/article/download/2175-7984.2012v11n22p155/23765. Acesso: 26 ago. 2021.

BASSUL, José Roberto. Reforma urbana e Estatuto da Cidade. EURE (Santiago) v.28 n.84 Santiago sep. 2002. Disponível em: https://scielo.conicyt.cl/scielo.php?pid=S0250-71612002008400008\&script=sci_arttext\&tlng=n. Acesso: 26 ago. 2021.

BRUNO FILHO, Fernando Guilherme. Princípios de direito urbanístico. Porto Alegre: Fabris Ed, 2015.

CORREA, Roberto Lobato. O espaço urbano. São Paulo: Palas Athena, 2004. 
COSTA, Beatriz Souza; VENÂNCIO, Stephanie Rodrigues. A função social da cidade e o direito à moradia digna como pressupostos do desenvolvimento urbano sustentável. Revista Direito Ambiental e sociedade, v. 6, n. 2.2016 (p. 106-136). Disponível em: http://www.ucs.com.br/etc/revistas/ index.php/direitoambiental/article/view/3481/2611. Acesso: 26 ago. 2021.

GOULART, Jefferson Oliveira; TERCI, Eliana Tadeu; OTERO, Estevam Vanale. Participação política e gestão urbana sob o Estatuto da Cidade. urbe. Revista Brasileira de Gestão Urbana (Brazilian Journal of Urban Management), 2015 jan./abr., 7(1), 122-135. Disponível em: https://www.scielo.br/j/urbe/a/ pdDjXyWfTxfgtwPYmYpfSgK/?lang=pt\&format=pdf. Acesso: 26 ago. 2021.

HADDAD, Paulo Roberto. Meio ambiente, planejamento e desenvolvimento sustentável. São Paulo: Saraiva, 2015.

HUMBERT, Georges Louis Hage. Direito urbanístico e função socioambiental da propriedade imóvel urbana. Belo Horizonte: Fórum, 2011.

IBAMA. Trajetórias, perspectivas e desafios da gestão ambiental pública. Coordenação de Gestão da Informação Ambiental. Brasília, DF: IBAMA,2020. Disponível em: https://biblioteca.ibge.gov.br/ visualizacao/livros/liv100643.pdf. Acesso: 26 ago. 2021.

IBGE, Coordenação de Geografia. Classificação e caracterização dos espaços rurais e urbanos do Brasil: uma primeira aproximação. Rio de Janeiro: IBGE, 2017. Disponível em: http://www.ibama.gov.br/phocadownload/publicacoes/Revistas/2020-08-04-ibama-cartilha_dos_artigos_2020.pdf. Acesso: 26 ago. 2021.

Pesquisa de Informações Básicas Municipais. Brasilia: IBGE, 2002. Disponível em: https:// biblioteca.ibge.gov.br/visualizacao/livros/liv6063.pdf. Acesso: 26 ago. 2021.

IDSC-BR, Índice de Desenvolvimento das Cidades - Brasil. Apresentação do Índice de Desenvolvimento das Cidades. Brasília, 2021. Disponível em: https://idsc-br.sdgindex.org/introduction. Acesso: 26 ago. 2021.

MUKAI, Toshio. Planejamento municipal: o plano diretor e o Estatuto da Cidade. Revista de Administração Municipal, 2005. Disponível em: http://lam.ibam.org.br/predownload.asp?area=4\&arq=plandir251_PB.PDF. Acesso: 26 ago. 2021.

MORETTI, Julia Azevedo. Estatuto da Cidade e preservação do meio ambiente urbano.

Cadernos Metrópole, núm. 16, julio-diciembre, 2006, pp. 109-120. Disponível em: https://www.redalyc. org/pdf/4028/402837798005.pdf. Acesso: 26 ago. 2021.

NETTO, Vinicius M; MEIRELLES, João; RIBEIRO, Fabiano. Cidade e interação: o papel do espaço urbano na organização social. urbe, Rev. Bras. Gest. Urbana 10 (2) May-Aug 2018. Disponível em: https://www.scielo.br/j/urbe/a/8YCDzpmQw3yFyYN6zNT88CH/abstract/?lang=pt. Acesso: 26 ago. 2021.

OLIVEIRA, Samuel Menezes; BRANDÃO, André da Fonseca. Regularização fundiária urbana: princípios específicos da Lei n 13.465 de 2017 e o princípio da prevenção à formação de ocupações irregulares. In.: Direito urbanístico-ambiental: uma visão epistêmica. Adir Ubaldo Rech, Juliana Cainelli de Almeida, Tamires Ravanello (org.). Caxias do Sul, RS: Educs, 2019. Disponível em: https:// www.ucs.br/site/midia/arquivos/ebook-direito-urbanistico.pdf. Acesso: 26 ago. 2021. 
PEREIRA, Polyana Faria; SCARDUA, Fernando Paiva. Espaços territoriais especialmente protegidos: conceito e implicações jurídicas. Ambient. soc. 11 (1) Jun 2008. Disponível em: https://www.scielo. br/j/asoc/a/ZQ47CM46G7jkwx53ztmqsxN/?lang=pt. Acesso: 26 ago. 2021.

PLANALTO. Lei n 10.257 de 10 de julho de 2001. DOU de 11.7.2001 e retificado em 17.7.2001. Disponível em: http://www.planalto.gov.br/ccivil_03/leis/leis_2001/110257.htm\#art58. Acesso: 26 ago. 2021. RODRIGUES, Arlete Moyses. Estatuto da Cidade: função social da cidade e da propriedade. Alguns aspectos sobre população urbana e espaço. Cadernos Metrópole, 12, 2004. Disponível em: http://repositorio.ipea.gov.br/bitstream/11058/3225/1/Livro_SociedadeeEconomia.pdf. Acesso: 26 ago. 2021. SANTIAGO, Mariana Ribeiro; PEIXOTO, Leonardo de Carvalho. A mobilidade urbana solidária no Estatuto da Cidade e sua concretização pela via da economia colaborativa. Revista de Direito da Cidade, vol. 11, no 2. ISSN 2317-7721 pp. 125-142. Disponível em: https://www.e-publicacoes.uerj.br/ index.php/rdc/article/view/36908/32462. Acesso: 26 ago. 2021.

SCOPEL, Vanessa. Planejamento urbano. Porto Alegre: SAGAH, 2018.

SICSÚ, João. A construção de uma estratégia de desenvolvimento. In.: Sociedade e economia: estratégias de crescimento e desenvolvimento. João Sicsú, Armando Castelar (org.). Brasília: Ipea, 2009. Disponível em: http://repositorio.ipea.gov.br/bitstream/11058/3225/1/Livro_SociedadeeEconomia. pdf. Acesso: 26 ago. 2021.

SDH, Secretária Nacional de Promoção e Defesa dos Direitos Humanos. Direito à moradia adequada. Brasília: Coordenação Geral de Educação em SDH, 2013. Disponível em: https://urbanismo.mppr. mp.br/arquivos/File/DH_moradia_final_internet.pdf. Acesso: 26 ago. 2021.

SILVA, Alex Dias da. A construção de políticas públicas para a sustentabilidade urbana. Revista Geografica da América Central. Número 65, julio-deciembre 2020. Disponível em: scielo.sa.cr/pdf/rge/ n65/2215-2563-rge-65-33.pdf. Acesso: 26 ago. 2021.

SILVA, Leticia Emanueli Cruz; CUNHA, Carlos Renato da. Instrumentos tributários no Estatuto da Cidade em prol da função social e do meio ambiente. Revista do Instituto de Direito Constitucional e Cidadania - IDCC, Londrina, v. 5, n. 1, p 10-30, jan/jul, 2020. Disponível em: http://revistadoidcc. com.br/index.php/revista/article/view/63/62. Acesso: 26 ago. 2021.

SILVA, Marcos Sousa e. Direto ambiental: principais princípios e seus reflexos na legislação e jurisprudência. Revista UNAERP, 2017. Disponível em: https://www.unaerp.br/revista-cientifica-integrada/ edicoes-anteriores/volume-3-edcao-2/2421-rci-direito-ambiental-principais-principios-e-seus-reflexos-na-legislacao-e-na-jurisprudencia/file. Acesso: 26 ago. 2021.

SOTTO et al, Debora. Sustentabilidade urbana: dimensões conceituais e instrumentos legais de implementação. USP Cidades globais Estud. av. 33 (97) Sep-Dec 2019. Disponível em: https://www.scielo. br/j/ea/a/zxSGtbCVxzKVSfZnGs3DWct/?lang=pt. Acesso: 26 ago. 2021.

SUNDFELD, Carlos Ari. O Estatuto da cidade e suas diretrizes gerais. In.: Estatuto da Cidade. Coords. Adilson Abreu Dallari e Sérgio Ferraz. São Paulo: Malheiros Editores, p. 44-60, 2014. 
TONELLA, Celene. Políticas urbanas no Brasil: marcos legais, sujeitos e instituições. Revista Sociedade e Estado - Volume 28 Número 1 - Janeiro/Abril 2013. Disponível em: https://www.scielo.br/j/se/a/ bJXnyw9HfzBzJb3nR6gx8CJ/?lang=pt\&format=pdf. Acesso: 26 ago. 2021. 